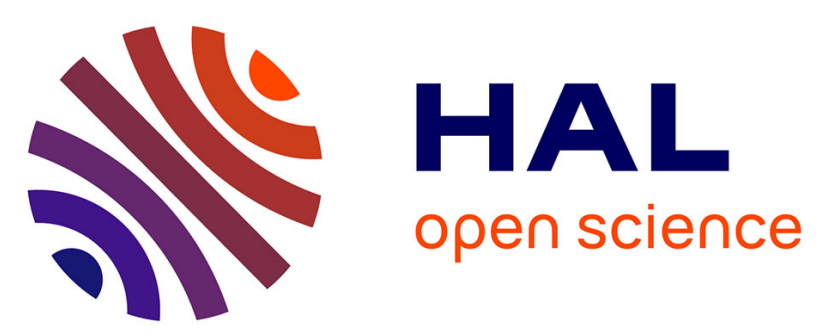

\title{
Monotonous consumption of fibre-enriched bread at breakfast increases satiety and influences subsequent food intake.
}

Peio Touyarou, Claire Sulmont-Rossé, Aude Gagnaire, Sylvie Issanchou, Laurent Brondel

\section{To cite this version:}

Peio Touyarou, Claire Sulmont-Rossé, Aude Gagnaire, Sylvie Issanchou, Laurent Brondel. Monotonous consumption of fibre-enriched bread at breakfast increases satiety and influences subsequent food intake.. Appetite, 2012, 58 (2), pp.575-81. 10.1016/j.appet.2011.11.026 . hal-00787919

\section{HAL Id: hal-00787919 https://hal.science/hal-00787919}

Submitted on 6 Jan 2022

HAL is a multi-disciplinary open access archive for the deposit and dissemination of scientific research documents, whether they are published or not. The documents may come from teaching and research institutions in France or abroad, or from public or private research centers.
L'archive ouverte pluridisciplinaire HAL, est destinée au dépôt et à la diffusion de documents scientifiques de niveau recherche, publiés ou non, émanant des établissements d'enseignement et de recherche français ou étrangers, des laboratoires publics ou privés. 


\section{MONOTONOUS CONSUMPTION OF FIBRE-ENRICHED BREAD}

\section{AT BREAKFAST INCREASES SATIETY AND INFLUENCES \\ 3 SUBSEQUENT FOOD INTAKE}

\section{Authors}

5 Peio Touyarou ${ }^{\mathrm{a}}$, Claire Sulmont-Rossé ${ }^{\mathrm{a}}$, Aude Gagnaire ${ }^{\mathrm{a}}$, Sylvie Issanchou ${ }^{\mathrm{a}}$ and Laurent

6 Brondel $^{\mathrm{a}, \mathrm{b}}$

\section{$7 \quad$ Addresses}

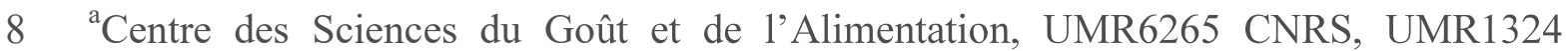

9 INRA, Université de Bourgogne, Agrosup Dijon, Dijon, France

$10{ }^{\mathrm{b}} \mathrm{CHU}$ de Dijon, Service d'Hépato-Gastroentérologie and UFR de Médecine de

11 l'Université de Bourgogne, Dijon, France.

\section{Corresponding author}

13 Peio Touyarou

14 Centre des Sciences du Goût et de l'Alimentation,

1517 rue Sully, 21000 Dijon, France.

16 E-mail: Peio.Touyarou@dijon.inra.fr

17 Tel: $+33(0) 380693410$, Fax: +33 (0)380693227 


\section{ABSTRACT}

This study aimed to observe the influence of the monotonous consumption of two

22 types of fibre-enriched bread at breakfast on hedonic liking for the bread, subsequent hunger and energy intake. Two groups of unrestrained normal weight participants were

24 given either white sandwich bread (WS) or multigrain sandwich bread (MG) at breakfast (the sensory properties of the WS were more similar to the usual bread eaten by the participants than those of the MG). In each group, two 15-day cross-over conditions were set up. During the experimental condition the usual breakfast of each participant was replaced by an isocaloric portion of plain bread (WS or MG). During the control condition, participants consumed only $10 \mathrm{~g}$ of the corresponding bread and completed their breakfast with other foods they wanted. The results showed that bread

31 appreciation did not change over exposure even in the experimental condition. Hunger

32 was lower in the experimental condition than in the control condition. The consumption

33 of WS decreased energy intake while the consumption of MG did not in the experimental condition compared to the corresponding control one. In conclusion, a monotonous breakfast composed solely of a fibre-enriched bread may decrease

36 subsequent hunger and, when similar to a familiar bread, food intake.

\section{Keywords}

38 Dietary fibre, weight loss, monotony, variety, staple foods, bread, food intake, satiety, 39 satiation, breakfast 
Introduction

Several studies have shown that a high-fibre diet may increase satiety and decrease energy intake (for recent studies see Lyly et al., 2009; Schroeder, Gallaher, Arndt, \& Marquart, 2009; Willis, Eldridge, Beiseigel, Thomas, \& Slavin, 2009). Several mechanisms have been put forward to explain the lower hunger/energy intake following the ingestion of dietary fibre (Burton-Freeman, 2000; Heaton, 1973; Howarth, Saltzman, \& Roberts, 2001; Tungland \& Meyer, 2002). Dietary fibre increases chewing, which is thought to reduce the rate of ingestion (Heaton, 1973). It increases

50 saliva and gastric juice production and therefore increases gastric volume (Norton, 51 Anderson, \& Hetherington, 2006; Rolls \& Roe, 2002). Furthermore, the gel-forming capacity of soluble fibre increases gastric distension (Burton-Freeman, 2000). This distension is involved in producing satiation during a meal (de Graaf, Blom, Smeets, Stafleu, \& Hendriks, 2004) and satiety between meals (Wang et al., 2008). Fibre decreases nutrient absorption in the intestine and thus reduces the metabolisable energy from available food (Baer, Rumpler, Miles, \& Fahey, 1997; Wisker, Maltz, \& Feldheim, 1988). Fibre, particularly soluble fibre, also increases chyme viscosity, thereby slowing transit time in the small intestine which triggers the secretion of Glucagon Like Peptide1 (Reimer \& McBurney, 1996), of cholecystokinin, of ghrelin (Weickert et al., 2006)

60 and of peptide YY (Reimer et al., 2010).

The aim of the present experiment was to assess whether replacing the usual breakfast of normal bodyweight participants by an isocaloric portion of fibre-enriched bread over several days would affect subsequent satiety and food intake. At first sight, it was expected that a fibre-enriched breakfast would reduce hunger sensation during the 
morning and decrease food intake during subsequent meals. However, it was unclear whether or not this effect would persist over several days (e.g. over repeated consumption) of fibre-enriched bread. In fact, several studies have shown that repeated monotonous - consumption of a food induces a decrease in pleasure for that food (Rolls \& de Waal, 1985; Schutz \& Pilgrim, 1958; Siegel \& Pilgrim, 1958). Thus, the repeated consumption of fibre-enriched bread may lead to a reduction in pleasure, which in turn may have an adverse effect on subsequent food intake. This question is obviously of particular interest to those who wish to promote better weight management through the consumption of "functional" food such as fibre-enriched foods.

This study was conducted using two types of fibre-enriched sandwich bread. In both types, the quantity of fibre was about five times higher than in a traditional French baguette. The ratio of soluble/insoluble fibre was similar between the two breads but the source of the fibre differed. One bread (White Sandwich - WS) was formulated to look like white sandwich bread because French consumers are used to eat white bread ( $75 \%$ of the bread eaten in France in 2009 was white bread). The other (Multigrain MG) bread actually looked like a multigrain bread with inclusions and was less familiar to French consumers. The choice of exposing participants to sandwich bread at breakfast was motivated by the work of de Castro (2007) who observed that a high level of carbohydrate consumed during the morning reduced total food intake for the rest of 84 the day.

The present experiment aimed to assess whether or not the effect of monotonous consumption of fibre-enriched bread could influence subsequent satiety and food intake, and whether such an effect depended on the type of bread eaten by the participants. 
89

\section{Design}

The two types of bread were tested in a between-subject design. For each group, the study consisted in two periods of 15 days. In one period, the experimental condition, the participants' breakfast consisted exclusively of fibre-enriched bread (i.e. WS or MG, depending on the group). For each participant, the quantity of bread consumed provided an energy intake that was similar to that of the participants' usual breakfast according to food diaries (see below). In the other period, the control condition, participants ate a small portion of fibre-enriched bread $(10 \mathrm{~g})$ and then completed their breakfast with the food of their choice. The quantity of fibre in such a small portion was negligible, but it allowed controlling for a possible effect of repeated exposure to the sensory characteristics of the bread that was independent from the effect of the fibre. For each condition, liking, hunger and food intake were measured and recorded at regular intervals (see below).

\section{Participants}

Participants were recruited by a local advertisement. All were bread eaters. To participate, candidates had to be aged between 20 and 45, have a Body Mass Index (BMI) between 19 and $25 \mathrm{~kg} / \mathrm{m}^{2}$ and be in the habit of eating breakfast, including at least one solid food, every day. Candidates also had to obtain a restriction score equal to or below 9 (Stunkard \& Messick, 1985). Finally, any candidates with food allergies, or who were undergoing medical treatment, or who smoked more than five cigarettes a day were excluded. The characteristics of both groups are presented in Table 1 . 
110 Individual informed consent was obtained before the experiment. The protocol was

111 approved by the ethics committee of Dijon, France (CPP-Est-I). Participants received a

$112 € 100$ fee for their participation.

113 Breads

114 The bread WS was enriched with fibres from wheat bran and formulated to look

115 like a white sandwich bread. The bread MG was enriched with fibres from other cereals

116 (oat, rye) and formulated to look like a multigrain bread with inclusions. Both breads

117 were provided by Gustalis (Longvic, France). Their composition is shown in Table 2.

118 Prior to the study, a Flash Profile (Dairou \& Sieffermann, 2002) was carried on the

119 two breads and on four branded breads belonging to the same product range with 32

120 participants different from the participants of the present study. Results showed that the

121 sensory characteristics of WS and MG breads were similar to the ones of the branded

122 breads. Specifically, the WS bread was characterized by a light colour, a soft texture

123 and a slightly sweet taste, while the MG bread was characterized by a slightly darker

124 colour and a larger number of inclusions corresponding to the grain particles. Given the

125 habits of French participants and the results of the Flash Profile, the WS bread

126 corresponded more to a "white bread" while the MG bread corresponded more to a

127 "multigrain bread".

128 Procedure

129 Food diaries

130 Before the study, participants recorded and weighed all foods and beverages

131 consumed at three consecutive regular breakfasts eaten at home (precision required was 
$132 \pm 1 \mathrm{~g}$ ). These diaries were then analysed using Bilnut software (S.C.D.A. Nutrisoft,

133 Cerelles, France) in order to calculate the usual energy intake for each participant at

134 breakfast and subsequently to determine the amount of bread (WS or MG) to be

135 consumed by each individual during the experimental period.

\section{Phases of exposure}

137 For each group (WS or MG), there were two periods of a fortnight each. During

138 the experimental condition, participants were required to consume the equivalent in

139 bread (WS or MG) of their usual energy intake. Participants were requested to eat the

140 bread plain, without butter or jam in order to avoid inter-individual differences. In fact,

141 without this constraint, some participants would have chosen to eat the bread with jam,

142 others with butter (or margarine) or with both jam and butter. In addition to the bread,

143 the participants were allowed to drink their usual beverage (e.g. coffee or tea). It should

144 be noted that in the experimental condition, the mean breakfast intake of dietary fibre

145 was not different between the WS group $(\mathrm{M}=14.9 ; \sigma=6 \mathrm{~g})$ and the MG group $(\mathrm{M}=21.6$;

$146 \sigma=10 \mathrm{~g})$. During the control condition, participants were required to consume $10 \mathrm{~g}$ of

147 WS or MG bread at each breakfast. They could complete their breakfast with their

148 usual food and drink choices.

149 The participants received their daily bread ration in separate freezing bags. They

150 were instructed to thaw the bread by placing it at room temperature the evening before

151 consumption. Breakfasts were eaten at home and participants were instructed not to

152 share their rations with other family members. They were also instructed to consume all

153 the bread provided at breakfast. In order to check compliance, participants were asked

154 to bring back their freezing bags each time they came to the laboratory for new 
supplying. Six participants ( 5 for the bread MG; 1 for the bread WS) brought back a small portion of non-eaten bread during the first days of the experiment but after further discussion, they adapted themselves to the ration.

At each breakfast, participants were required to give a hedonic rating for the bread at the first mouthful. Participants were also asked to rate their sensation of hunger

160 before breakfast, immediately after breakfast, at 10 am and at noon. These assessments were made on visual analogue scales of $10 \mathrm{~cm}$ anchored at each end ("Extremely unpleasant" / "Extremely pleasant" and "I am not hungry at all" / "I am extremely hungry", respectively). On the second, sixth, tenth and fourteenth day of each phase of

164 exposure (D2, D6, D10, D14), participants were also required to record and accurately

165 weigh all foods and beverages consumed during the day (Clatronic KW204 scale, 166 Kempen, Germany, precision required: $1 \mathrm{~g})$.

\section{Data analysis}

The grades on the scales were converted into scores from 0 to 10 by measuring the distance between the left anchor and the mark made by the participant. The food diaries filled in during the two periods were analysed using Bilnut software (S.C.D.A.

171 Nutrisoft, Cerelles, France) to determine the total energy intake per meal and per day 172 (breakfast, lunch and dinner).

The evolution of various parameters (hunger, pleasure, energy, carbohydrate, fat and protein intakes) during the periods was modelled using a linear mixed model with condition as a fixed effect, and exposure and participant as random effects. For the

176 random element, an appropriate correlation structure was sought to account for possible

177 correlations between measurements taken at different times for a given participant. A 
compound symmetry (CS) correlation structure was chosen because it led to the lowest

179 Akaike criterion (AIC) for most of the parameters. Only linear factors were retained in

180 the final models (Table 3), as the quadratic factors (exposure ${ }^{2}$ and exposure ${ }^{2}$ xcondition)

181 were not significant. Statistical analyses were performed using the MIXED procedure of SAS software (SAS Institute Inc., Cary, NC, USA).

\section{Results}

Effect of repeated consumption of a fibre-enriched bread at breakfast on the hedonic

\section{liking of this bread}

Fig. 1 shows the evolution of liking scores during consumption of the first

187 mouthful of bread at breakfast, according to the condition and the bread consumed.

188 Marginal ANOVA obtained with the general linear model did not reveal any condition effect for the WS bread (Table 3). No difference in liking for the first mouthful of bread at breakfast between the experimental condition and the control condition for the WS bread (experimental condition: $M=5.1$, S.D. $=2.6$; control condition: $M=4.9$, S.D. $=$

192 2.6) was observed. In contrast, a significant condition effect was observed for the MG

193 bread: participants appreciated this bread less in the experimental condition $(M=5.1$,

194 S.D. $=2.7)$ than in the control condition $(M=6.0$, S.D. $=2.7)$. As, in both conditions, participants gave their hedonic rating at the first mouthful, this difference may be

196 related to what they have to eat. So, their expectations were lower when they had to eat

197 a large quantity than when they had to eat just a mouthful. Liking for the breads did not

198 decrease over repeated consumptions: in fact regardless of the bread consumed, the 
exposure effect was not significant. Moreover, the exposure*condition interaction was not significant.

Effect of repeated consumption of a fibre-enriched bread at breakfast on subsequent sensation of hunger

Fig. 2 shows the evolution of the sensation of hunger at four times of the day: before breakfast, after breakfast, at mid-morning and at noon, for both the WS and MG bread. For the WS bread, ANOVA did not reveal any significant condition effect before breakfast: the sensation of hunger in the experimental condition $(M=4.9$, S.D. $=2.7)$ was not different from that in the control condition $(M=5.0$, S.D. $=2.7)$. In contrast, a condition effect was observed immediately after breakfast, at 10 am and at noon. At each of these times, the sensation of hunger was rated lower in the case of the experimental condition (after breakfast: $M=1.0$, S.D. $=1.5$; at 10 am: $M=1.7$, S.D. $=$

211 1.7; at noon: $M=4.4$, S.D. $=3.9$ ) than for the control condition (after breakfast: $M=$ 2.0, S.D. $=2.2$, at $10 \mathrm{am}: M=2.7$, S.D. $=2.5$; at noon: $M=5.2$, S.D. $=2.8)$. A significant exposure effect was also observed for measurements at 10 am and at noon,

214 showing an increase in hunger ratings at both of these times over subsequent days of the 215 study.

216 For the MG bread, a condition effect was observed before breakfast: the hunger

217 rating was slightly lower in the experimental condition $(M=5.3$, S.D. $=2.4)$ than in the 218 control condition $(M=5.6$, S.D. $=2.8)$. This effect was nonetheless slight compared to

219 the significant condition effect observed at 10 am and at noon. Once again, at each of 220 these times, the sensation of hunger was rated lower in the experimental condition (at 10 221 am: $M=2.4$, S.D. $=2.4$; at noon: $M=6.0$, S.D. $=2.7$ ) than in the control condition (at 
10 am: $M=3.5$, S.D. $=2.7$; at noon: $M=6.8$, S.D. $=2.1$ ). An exposure effect was also observed for the evaluations before breakfast, immediately after breakfast and at noon, showing a decrease in hunger ratings just before and just after breakfast over subsequent days of the study on the one hand, and an increase at noon on the other.

\section{Effect of repeated consumption of a fibre-enriched bread at breakfast on energy}

\section{intake throughout the day}

Fig. 3 shows the evolution of the total energy intake at breakfast and for the rest of the day during each period of exposure (D2, D6, D10 and D14). For intake at breakfast, marginal ANOVA did not reveal any significant condition, exposure or exposure $^{*}$ condition effect, regardless of the group considered (Table 3). The energy intake for the experimental condition (WS bread: $M=392 \mathrm{kcal}$, S.D. $=173$; MG bread: $M=393 \mathrm{kcal} ;$ S.D. $=148)$ was not different from the energy intake for the control condition (WS bread: $M=394$ kcal; S.D. $=241$; MG bread: $M=354$ kcal; S.D. $=207$ ).

These results therefore demonstrated that at breakfast, energy intake for the experimental condition was equivalent to the energy intake for the control condition, during which participants supplemented the required consumption of $10 \mathrm{~g}$ of bread with their usual food and beverage choices.

Regarding the energy intake calculated for the rest of the day, data analysis revealed a significant condition effect for both the WS bread and the MG bread, but these effects were opposite (Table 3 and Figure 3). In fact, for the WS bread the experimental condition reduced energy intake for the rest of the day compared to the control condition (mean 4 days values $M=1263 \mathrm{kcal}$; S.D. $=120$ and $M=1424 \mathrm{kcal}$; S.D. $=120$ respectively). In contrast, for the MG bread the experimental condition 
245 increased energy intake for the rest of the day compared to the control condition $(M=$

$2461408 \mathrm{kcal} ;$ S.D. $=85$ and $M=1261 \mathrm{kcal}$; S.D. $=85$ respectively). The exposure and

247 exposure ${ }^{*}$ condition effects were not significant for either type of bread. The same

248 pattern of results was observed when intakes were analysed per meal (lunch, dinner)

249 (data not shown).

250 Discussion

251 In accordance with the hypotheses, replacing the participants' breakfast with a

252 monotonous consumption of fibre-enriched bread (WS or MG) led to a decrease in the

253 sensation of hunger during the morning. However, the decrease in hunger coincided

254 with a decrease in subsequent energy intake for the WS bread, but an increase in energy

255 intake for the MG bread. Results also showed that repeated consumption of these types

256 of bread at breakfast did not lead to decreased liking for the breads over the course of

257 the study, even in the experimental condition.

258 Data in the literature has shown that repeated - monotonous - consumption of a

259 food generated a decrease in intake and/or in liking for that food (Cabanac \& Rabe,

260 1976; Rolls \& de Waal, 1985; Zandstra, de Graaf, \& van Trijp, 2000). For instance,

261 Cabanac and Rabe (1976) observed a reduction of 25 to $50 \%$ in food intake when

262 normal weight subjects were given a complete liquid diet everyday, at each meal, for

263 three consecutive weeks. In an unpublished study conducted in our laboratory, ten

264 unrestrained participants of normal weight ate the same food exclusively - ravioli - at

265 every meal for three consecutive days (for breakfast, lunch and dinner). The results

266 showed a significant reduction in overall food intake (-33\% on the third day) compared 
to a control situation. Zandstra et al. (2000) observed that consumption of a savoury sauce once a week for ten consecutive weeks resulted in a decrease in the amount of sauce consumed, even though the participants could combine the sauce with the food of

270 their choice. Concurrent with this decrease, Zandstra and colleagues (2000) observed a

271 decrease in hedonic liking for these sauces. However, several authors have observed

272 that repeated consumption of "staple foods" did not affect their hedonic liking

273 (Hetherington, Pirie, \& Nabb, 2002; Kamen \& Peryam, 1961; Meiselman, de Graaf, \&

274 Lesher, 2000). The FAO defines staple foods as foods that are eaten regularly and in

275 such quantities as to constitute the dominant part of the diet and supply a major

276 proportion of energy and nutrient needs. Staple foods are generally cereal products that

277 constitute a major part of a diet and are culture-specific (e.g., bread in France, rice in

278 Southeast Asia). Meiselman et al (2000) focused on the evolution in liking for a food

279 which is initially highly palatable - chocolate - compared to a moderately palatable food

280 belonging to the staple food category - buttered bread - over the course of repeated

281 consumption (once a day for 22 days). The results showed that liking for chocolate

282 decreased greatly over the course of subsequent consumption, while liking for buttered

283 bread remained close to its initial level. Consequently, Meiselman and colleagues

284 suggested characterising staple foods as "staple components of a diet [that] are resistant

285 to monotony effects". Due to their predominance in a population's diet and to their

286 resistance to the monotony effect, it has been suggested that staple foods could be used

287 to fight against certain food disorders. Bouis (2000) and Welch and Graham (2004)

288 suggested enriching staple foods with macronutrients in order to combat nutritional

289 deficiencies caused by under-nutrition. Conversely, improving the nutritional quality of

290 staple foods could be a useful means to prevent and/or treat diabetes and obesity (Franz 
et al., 2002; Thompson et al., 2005). The present study confirmed that repeated consumption of a large quantity of bread did not induce lassitude for bread. These results substantiate the advantages of bread as a way to improve the nutritional quality

294 of diets for French people.

296 intake after the WS bread could be attributed to the presence of dietary fibre. In fact,

297 some studies have shown that repeated consumption of a fibre-enriched food can lead to 298 a reduction in energy intake and weight in obese patients (Rössner, Von Zweigbergk, 299 Öhlin, \& Ryttig, 1987; Stevens et al., 1987). Pasman and colleagues (Pasman, Saris, 300 Wauters, \& Westerterp-Plantenga, 1997) showed that the consumption of orange juice 301 containing a guar gum supplement (soluble fibre) for a week led to a decreased sensation of hunger, resulting in reduced energy intake, compared to a control situation where participants received orange juice without added fibre. In accordance with these results, we observed that replacing a standard breakfast with an isocaloric amount of WS bread led to a decreased sensation of hunger during the morning and a reduction in subsequent energy intake. In contrast, while replacing breakfast with an isocaloric

307 amount of MG bread also led to a decreased sensation of hunger, this decrease did not 308 result in a reduced caloric intake. On the contrary, in the experimental condition for this bread, participants slightly increased their caloric intake during subsequent eating 310 events.

311 The difference between the effect of WS and MG bread consumption on

312 subsequent food intake, albeit a similar decrease in hunger sensation in both conditions, 313 underlines the fact that measurement of the sensation of hunger (as performed here with 314 visual analogue scales) does not always predict actual food intake. A number of studies 
315 have shown relationships between measurements of hunger and food intake (e.g. de

316 Castro \& Elmore, 1988) but Mattes (1990) noted that rating the sensation of hunger is a

317 learned rather than an innate reflection of the systems that control appetite. Beyond this

318 methodological aspect, several hypotheses can be proposed to explain why the

319 decreased sensation of hunger induced inconsistent reductions in energy intake.

320 One possible explanation relates to the nature of the fibre used to formulate WS

321 and MG bread. In fact, some authors evidenced that the origin of fibre might play a role

322 in the decrease in hunger sensation or caloric intake. For example, Hlebowicz et al.

323 (2007) did not observe any difference in hunger ratings after ingestion of cereal bran

324 flakes, wholemeal oat flakes or corn flakes. On the contrary, Willis et al. (2009)

325 observed that participants were less hungry after ingestion of a preload of muffins with

326 resistant starch or corn bran than muffins with barley oat. Furthermore, some authors

327 observed that an ingestion of fibre led to a dissociation between hunger and food intake

328 (e.g., Schroeder et al., 2009) whereas others observed that a decrease in hunger

329 sensation led to a decrease in subsequent energy intake (e.g., Lee et al., 2006). Another

330 possible explanation to explain the differential effect of the two breads on energy intake

331 could be related to the difference in liking between the experimental and the control

332 conditions that was observed for the MG bread but not for the WS bread. It is possible

333 that having to eat a relatively large amount of the MG bread induced a feeling of

334 "discomfort" among participants. Participants may then have compensated for this

335 "discomfort" by increasing their subsequent food intake. A last explanation relates to

336 cognitive associations related to the appearance of the bread. Participants may have

337 associated the MG bread with a high fibre-content (in fact, it was formulated to look

338 like multigrain bread), and, in turn, to low caloric foods. Thus, it is possible that 
339 subjects ate more on the rest of day as they erroneously believed that they had a low

340 energy breakfast when they had MG bread in comparison to WS bread. However, those

341 hypotheses deserve further evaluation. A better understanding of the physiological

342 and/or psychological mechanisms responsible or not of the decrease of subsequent food

343 intake after fibre ingestion could be a challenge for future studies.

\section{Conclusion}

345 The present study indicates that the consumption of a monotonous enriched-fibre

346 bread decrease the subsequent sensation of hunger without affecting liking for bread.

347 However, while this decrease in hunger led to a decrease in subsequent food intake for

348 the more familiar bread, it did not for the less familiar one. This underlines the

349 importance of developing healthy staple foods that are not too different from the foods

350 we are used to; otherwise they may not lead to the expected beneficial effects.

\section{Acknowledgements}

We thank Gustalis ${ }^{\circledR}$ for the production of the breads. We also thank Philip

353 Bastable ('Pôle de Recherche', Dijon University Hospital), E.P. Köster (CICS,

354 Wageningen University and Research) and Luc Pénicaud (UMR CSGA, Dijon) for

355 revising the paper. This work was financed by the French government under the FUI

356 (Fond Unique Interministériel) programme through the project Farine.+ 


\section{References}

358 Baer, D. J., Rumpler, W. V., Miles, C. W., \& Fahey, G. C. (1997). Dietary fiber decreases the metabolizable energy content and nutrient digestibility of mixed diets fed to humans. The Journal of Nutrition, 127, 579-586.

Bouis, H. E. (2000). Enrichment of food staples through plant breeding: A new strategy for fighting micronutrient malnutrition. Nutrition, 16, 701-704.

Burton-Freeman, B. (2000). Dietary fiber and energy regulation. The Journal of Nutrition, 130, 272S-275S.

Cabanac, M., \& Rabe, E. F. (1976). Influence of a monotonous food on body weight regulation in humans. Physiology \& Behavior, 17, 675-678.

Dairou, V., \& Sieffermann, J.-M. (2002). A comparison of 14 jams characterized by conventional profile and a quick original method, the flash profile. Journal of Food Science, 67, 826-834.

de Castro, J., M. (2007). The time of day and the proportions of macronutrients eaten are related to total daily food intake. British Journal of Nutrition, 98, 1077-1083.

de Castro, J. M., \& Elmore, D. K. (1988). Subjective hunger relationships with meal patterns in the spontaneous feeding-behavior of humans - Evidence for a causal

de Graaf, C., Blom, W. A. M., Smeets, P. A. M., Stafleu, A., \& Hendriks, H. F. J. Nutrition, 79, 946-961.

Franz, M. J., Bantle, J. P., Beebe, C. A., Brunzell, J. D., Chiasson, J.-L., Garg, A., Holzmeister, L. A., Hoogwerf, B., Mayer-Davis, E., Mooradian, A. D., Purnell, J. Q., \& Wheeler, M. (2002). Evidence-based nutrition principles and 
recommendations for the treatment and prevention of diabetes and related complications. Diabetes Care, 25, 148-198.

383

384

Heaton, K. W. (1973). Food fibre as an obstacle to energy intake. The Lancet, 302, $1418-1421$.

Hetherington, M. M., Pirie, L. M., \& Nabb, S. (2002). Stimulus satiation: effects of repeated exposure to foods on pleasantness and intake. Appetite, 38, 19-28.

Hlebowicz, J., Wickenberg, J., Fahlstrom, R., Bjorgell, O., Almer, L.-O., \& Darwiche, G. (2007). Effect of commercial breakfast fibre cereals compared with corn flakes on postprandial blood glucose, gastric emptying and satiety in healthy subjects: a randomized blinded crossover trial. Nutrition Journal, 6, 22, doi:10.1186/1475-2891-6-22.

Howarth, N. C., Saltzman, E., \& Roberts, S. B. (2001). Dietary fiber and weight regulation. Nutrition Reviews, 59, 129-139.

Kamen, J. M., \& Peryam, D. R. (1961). Acceptability of repetitive diets. Food Technology, 15, 173-177.

Lee, Y. P., Mori, T. A., Sipsas, S., Barden, A., Puddey, I. B., Burke, V., Hall, R. S., \& Hodgson, J. M. (2006). Lupin-enriched bread increases satiety and reduces energy intake acutely. American Journal of Clinical Nutrition, 84, 975-980.

Lyly, M., Liukkonen, K. H., Salmenkallio-Marttila, M., Karhunen, L., Poutanen, K., \& Lahteenmaki, L. (2009). Fibre in beverages can enhance perceived satiety. European Journal of Nutrition, 48, 251-258.

Mattes, R. (1990). Hunger ratings are not a valid proxy measure of reported food-intake in humans. Appetite, 15, 103-113. 
404 Meiselman, H. L., de Graaf, C., \& Lesher, L. L. (2000). The effects of variety and monotony on food acceptance and intake at a midday meal. Physiology \& Behavior, 70, 119-125.

Norton, G. N., Anderson, A. S., \& Hetherington, M. M. (2006). Volume and variety: relative effects on food intake. Physiology \& Behavior, 87, 714-722.

Pasman, W. J., Saris, W. H. M., Wauters, M. A. J., \& Westerterp-Plantenga, M. S. (1997). Effect of one week of fibre supplementation on hunger and satiety ratings and energy intake. Appetite, 29, 77-87.

Reimer, R. A., \& McBurney, M. I. (1996). Dietary fiber modulates intestinal proglucagon messenger ribonucleic acid and postprandial secretion of glucagonlike peptide-1 and insulin in rats. Endocrinology, 137, 3948-3956.

Reimer, R. A., Pelletier, X., Carabin, I. G., Lyon, M., Gahler, R., Parnell, J. A., \& Wood, S. (2010). Increased plasma PYY levels following supplementation with the functional fiber PolyGlycopleX in healthy adults. European Journal of Clinical Nutrition, 64, 1186-1191.

419 Rolls, B. J., \& Roe, L. S. (2002). Effect of the volume of liquid food infused intragastrically on satiety in women. Physiology \& Behavior, 76, 623-631. from an Ethiopian refugee camp. Physiology \& Behavior, 34, 1017-1020. reduction with dietary fibre supplements. Acta Medica Scandinavica, 222, 8388. 
Schroeder, N., Gallaher, D. D., Arndt, E. A., \& Marquart, L. (2009). Influence of whole grain barley, whole grain wheat, and refined rice-based foods on short-term satiety and energy intake. Appetite, 53, 363-369.

Schutz, H. G., \& Pilgrim, F. J. (1958). A field study of food monotony. Psychological Reports, 4, 559-565.

Siegel, P. S., \& Pilgrim, F. J. (1958). The effect of monotony on the acceptance of food. The American Journal of Psychology, 71, 756-759.

Stevens, J., Levitsky, D. A., VanSoest, P. J., Robertson, J. B., Kalkwarf, H. J., \& Roe, D. A. (1987). Effect of psyllium gum and wheat bran on spontaneous energy intake. American Journal of Clinical Nutrition, 46, 812-817.

Stunkard, A. J., \& Messick, S. (1985). The three-factor eating questionnaire to measure dietary restraint, disinhibition and hunger. Journal of Psychosomatic Research, 29, 71-83.

Thompson, W. G., Rostad Holdman, N., Janzow, D. J., Slezak, J. M., Morris, K. L., \& Zemel, M. B. (2005). Effect of energy-reduced diets high in dairy products and fiber on weight loss in obese adults. Obesity, 13, 1344-1353.

Tungland, B. C., \& Meyer, D. (2002). Nondigestible oligo- and polysaccharides (dietary fiber): Their physiology and role in human health and food. Comprehensive Reviews in Food Science and Food Safety, 1, 90-109.

Wang, G.-J., Tomasi, D., Backus, W., Wang, R., Telang, F., Geliebter, A., Korner, J., Bauman, A., Fowler, J. S., Thanos, P. K., \& Volkow, N. D. (2008). Gastric distention activates satiety circuitry in the human brain. Neuroimage, 39, 18241831. 
449 Welch, R. M., \& Graham, R. D. (2004). Breeding for micronutrients in staple food crops from a human nutrition perspective. Journal of Experimental Botany, 55, 353-364.

452 Willis, H. J., Eldridge, A. L., Beiseigel, J., Thomas, W., \& Slavin, J. L. (2009). Greater satiety response with resistant starch and corn bran in human subjects. Nutrition Research, 29, 100-105.

455 Wisker, E., Maltz, A., \& Feldheim, W. (1988). Metabolizable energy of diets low or high in dietary fiber from cereals when eaten by humans. The Journal of Nutrition, 118, 945-952.

458 Zandstra, E. H., de Graaf, C., \& van Trijp, H. C. M. (2000). Effects of variety and repeated in-home consumption on product acceptance. Appetite, 35, 113-119.

460

461

462 
463 Table 1: Characteristics of the participants

\begin{tabular}{|c|c|c|}
\hline & WS Group (n=16) & MG Group (n=22) \\
\hline Gender (male / female) & $8 / 8$ & $12 / 10$ \\
\hline Age (mean \pm sem years) & $25.9 \pm 1.2$ & $30.2 \pm 1.5$ \\
\hline BMI $\left(\right.$ mean \pm sem kg.m $\left.{ }^{-2}\right)$ & $22.8 \pm 0.5$ & $22.3 \pm 0.4$ \\
\hline Restriction score (mean \pm sem) & $4.6 \pm 0.5$ & $4.5 \pm 0.4$ \\
\hline
\end{tabular}


467 Table 2: Energy content and composition of the two types of bread.

\begin{tabular}{lcc}
\hline & WS Bread & MG Bread \\
\hline Energy content $(\mathrm{kcal} / 100 \mathrm{~g})$ & 211.4 & 228.8 \\
Carbohydrates $(\mathrm{g} / 100 \mathrm{~g})$ & 37.7 & 36.8 \\
Lipids $(\mathrm{g} / 100 \mathrm{~g})$ & 3.2 & 3.8 \\
Proteins $(\mathrm{g} / 100 \mathrm{~g})$ & 8.0 & 11.8 \\
Dietary fibre $(\mathrm{g} / 100 \mathrm{~g})$ & 10.4 & 12.8 \\
Ratio soluble/insoluble fibre & $30 / 70$ & $33 / 67$ \\
\hline
\end{tabular}

468

469 
470 Table 3: Hedonic score, hunger and food intake ( $F$ and $p$ values) for the WS group and the MG

471 group. Significant effects are in bold characters.

\begin{tabular}{|c|c|c|c|c|c|c|}
\hline \multirow{2}{*}{ Parameter } & \multirow{2}{*}{$\begin{array}{l}\text { Time of } \\
\text { measurement }\end{array}$} & \multirow{2}{*}{ Factors } & \multicolumn{2}{|c|}{ WS Group } & \multicolumn{2}{|c|}{ MG Group } \\
\hline & & & $F$ & $p$ & $F$ & $p$ \\
\hline \multirow{3}{*}{ Hedonic score } & \multirow{3}{*}{ First mouthful } & Condition & 1.81 & 0.20 & 56.82 & $<0.001$ \\
\hline & & Exposure & 0.00 & 0.98 & 1.19 & 0.27 \\
\hline & & Condition $\times$ Exposure & 1.05 & 0.31 & 3.58 & 0.06 \\
\hline \multirow[t]{12}{*}{ Hunger } & \multirow[t]{3}{*}{ Before breakfast } & Condition & 0.29 & 0.60 & 4.45 & 0.05 \\
\hline & & Exposure & 3.53 & 0.06 & 6.03 & 0.01 \\
\hline & & Condition $\times$ Exposure & 3.04 & 0.08 & 0.02 & 0.90 \\
\hline & \multirow[t]{3}{*}{ After breakfast } & Condition & 69.7 & $<0.001$ & 3.26 & 0.08 \\
\hline & & Exposure & 0.07 & 0.78 & 11.81 & $<0.001$ \\
\hline & & Condition $\times$ Exposure & 3.28 & 0.07 & 3.36 & 0.07 \\
\hline & \multirow[t]{3}{*}{ At $10 \mathrm{am}$} & Condition & 49.90 & $<0.001$ & 39.32 & $<0.001$ \\
\hline & & Exposure & 11.27 & 0.009 & 2.70 & 0.10 \\
\hline & & Condition $\times$ Exposure & 0.56 & 0.45 & 0.15 & 0.63 \\
\hline & \multirow[t]{3}{*}{ At noon } & Condition & 14.77 & 0.002 & 20.73 & $<0.001$ \\
\hline & & Exposure & 6.08 & 0.01 & 4.16 & 0.04 \\
\hline & & Condition $\times$ Exposure & 0.22 & 0.64 & 1.56 & 0.21 \\
\hline \multirow[t]{18}{*}{ Food Intake } & \multirow[t]{3}{*}{ Daily } & Condition & 4.56 & 0.05 & 10.69 & 0.004 \\
\hline & & Exposure & 4.31 & 0.04 & 0.44 & 0.51 \\
\hline & & Condition $\times$ Exposure & 1.81 & 0.18 & 2.22 & 0.14 \\
\hline & \multirow[t]{3}{*}{ Breakfast } & Condition & 0.01 & 0.93 & 3.68 & 0.07 \\
\hline & & Exposure & 0.07 & 0.79 & 1.01 & 0.32 \\
\hline & & Condition $\times$ Exposure & 0.22 & 0.64 & 0.23 & 0.63 \\
\hline & \multirow[t]{3}{*}{ Lunch } & Condition & 2.79 & 0.12 & 0.34 & 0.57 \\
\hline & & Exposure & 4.49 & 0.04 & 0.07 & 0.80 \\
\hline & & Condition $\times$ Exposure & 0.22 & 0.64 & 0.34 & 0.56 \\
\hline & \multirow[t]{3}{*}{ Dinner } & Condition & 5.57 & 0.03 & 3.02 & 0.09 \\
\hline & & Exposure & 0.84 & 0.36 & 0.02 & 0.88 \\
\hline & & Condition $\times$ Exposure & 0.71 & 0.40 & 1.46 & 0.23 \\
\hline & \multirow[t]{3}{*}{ Snack } & Condition & 0.02 & 0.89 & 2.70 & 0.11 \\
\hline & & Exposure & 0.23 & 0.63 & 1.05 & 0.31 \\
\hline & & Condition $\times$ Exposure & 0.86 & 0.36 & 2.87 & 0.09 \\
\hline & \multirow{3}{*}{$\begin{array}{l}\text { Daily minus } \\
\text { Breakfast }\end{array}$} & Condition & 4.61 & 0.05 & 5.89 & 0.02 \\
\hline & & Exposure & 0.34 & 0.56 & 0.19 & 0.66 \\
\hline & & Condition $\times$ Exposure & 0.43 & 0.51 & 1.85 & 0.18 \\
\hline
\end{tabular}

472 Condition levels: experimental and control. 
475 Fig. 1. Evolution of bread liking scores during the control condition (hatched line)

476 versus the experimental condition (full line) for each type of fibre-enriched bread (white

477 sandwich bread - WS - on the left; multigrain bread - MG - on the right). Results are

478 expressed as mean and SEM.

479 Fig. 2. Evolution in hunger sensation before breakfast, after breakfast, at 10 am and at 480 noon during the control condition (hatched line) versus the experimental condition (full 481 line) for each type of fibre-enriched bread (white sandwich bread - WS - on the left; 482 multigrain bread - MG - on the right). Results are expressed as mean and SEM.

483 Fig. 3. Evolution of the energy intake at breakfast and during the rest of the day (total 484 daily energy intake minus Breakfast energy intake, Table 3) during the control condition 485 (hatched line) versus the experimental condition (full line) for each type of fibre486 enriched bread (white sandwich bread - WS - on the left; multigrain bread - MG - on 487 the right). Results are expressed as mean and SEM. 
490
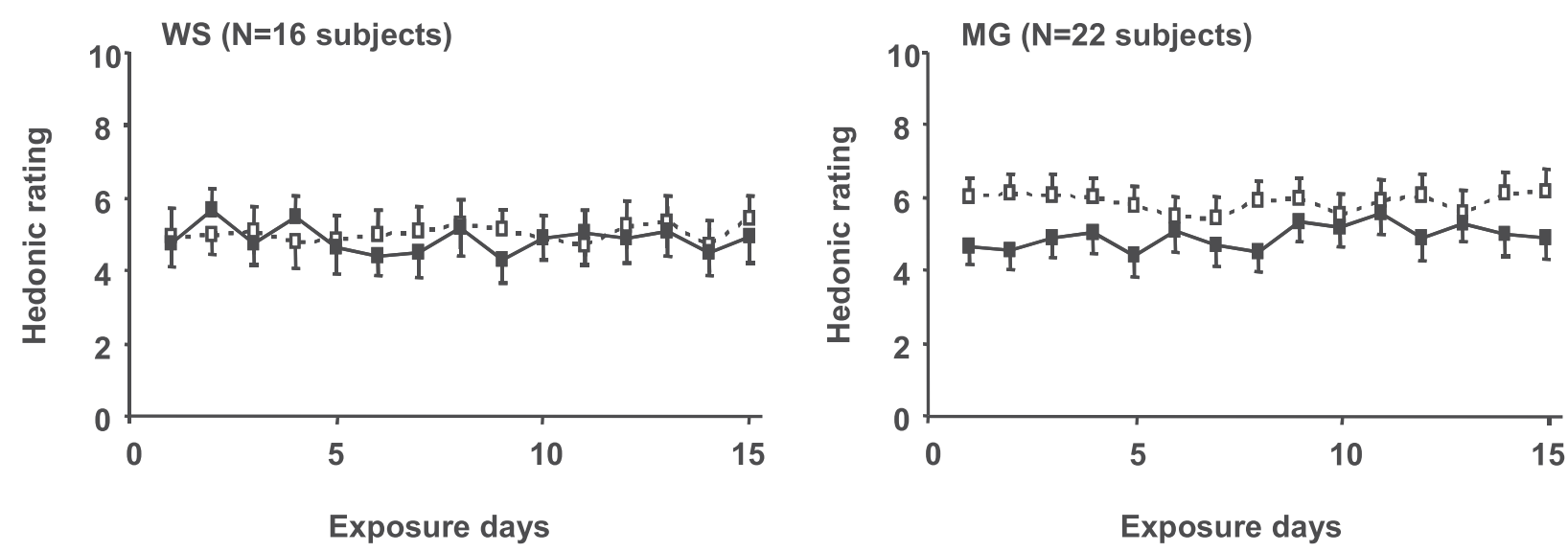

491

Exposure days

Exposure days

492 

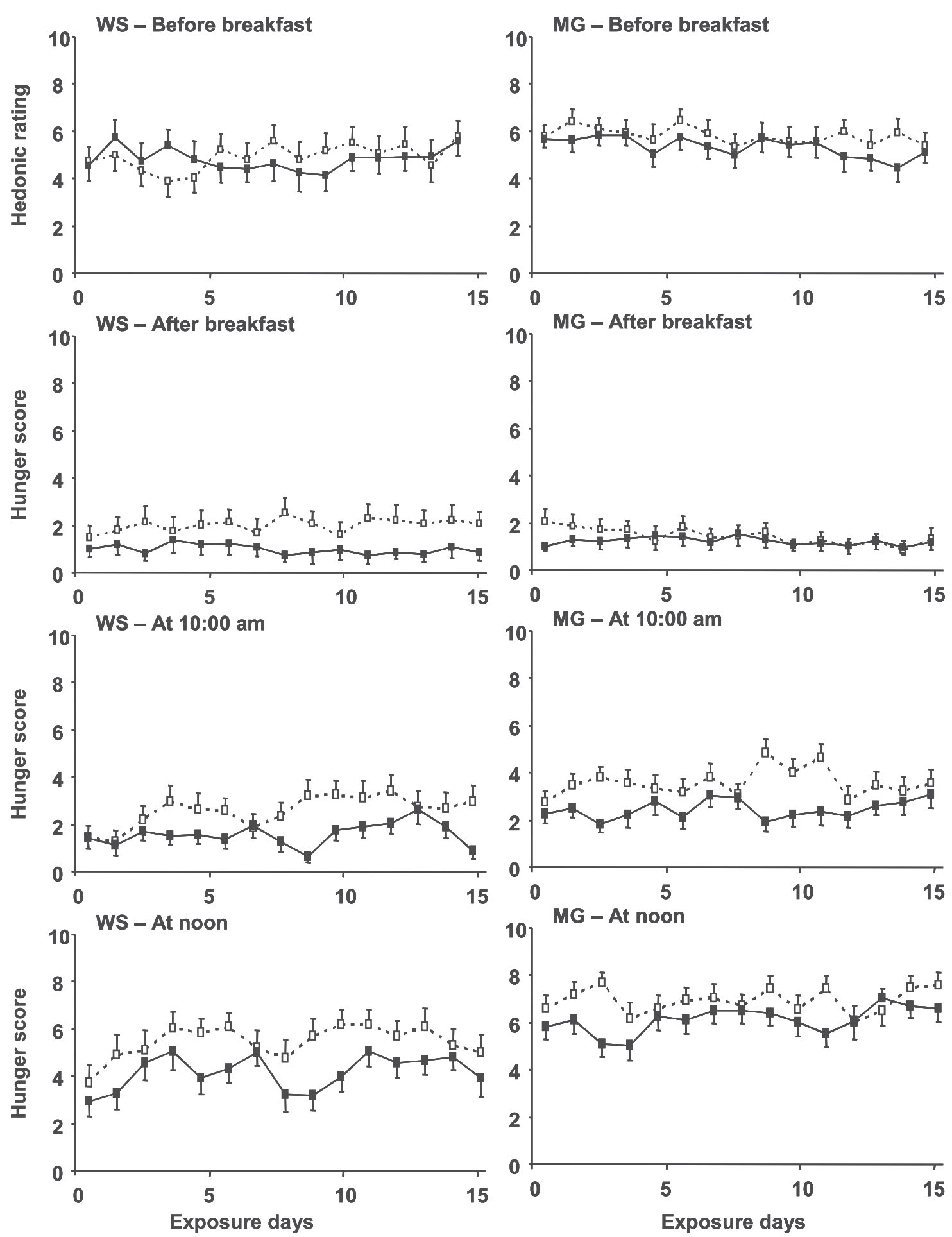

494 

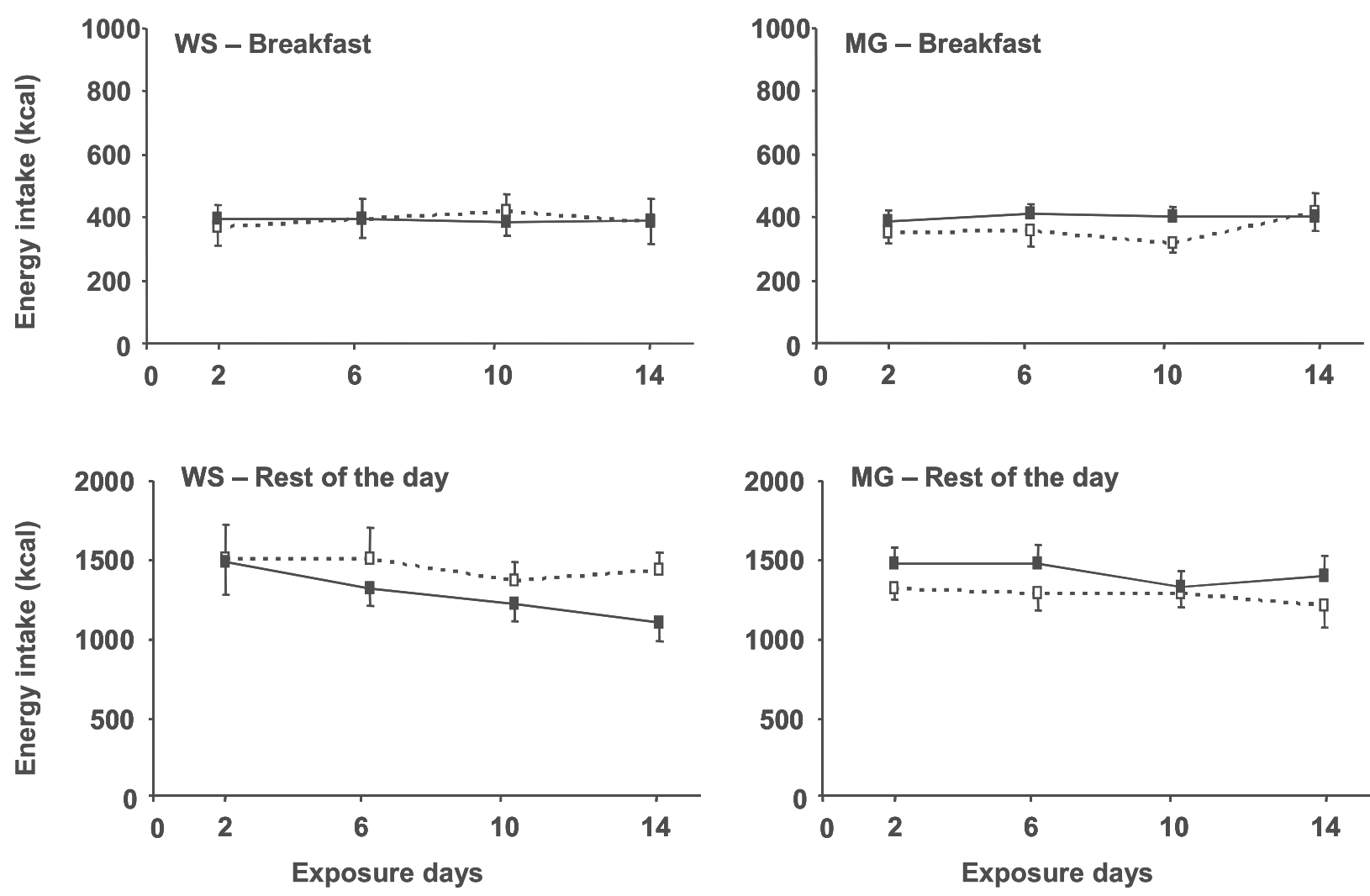

497

498

499 